Proceedings of the 33rd Annual Meeting of the Brazilian Embryo Technology Society (SBTE); Ilha de Comandatuba, BA, Brazil, August 15th to 19th, 2019.

\title{
Strategies to increment in vivo and in vitro embryo production and transfer in cattle
}

\author{
Gabriel A. Bó ${ }^{1,2,3, *}$, Andrés Cedeño ${ }^{1,3,4}$, Reuben J. Mapletoft ${ }^{5}$ \\ ${ }^{1}$ Instituto de Reproducción Animal Córdoba (IRAC), Zona Rural General Paz, (5145) Córdoba, Argentina. \\ ${ }^{2}$ Instituto de Ciencias Básicas, Medicina Veterinaria, Universidad Nacional de Villa María, Villa del Rosario, \\ Córdoba, Argentina. \\ ${ }^{3}$ Doctorado en Ciencias Mención Agroalimentos, Universidad Nacional de Villa Maria, Villa del Rosario, Córdoba, Argentina. \\ ${ }^{4}$ Laboratorio de Biotecnologías de la Reproducción Animal, Medicina Veterinaria, Escuela Superior Politécnica Agropecuaria de \\ Manabí (ESPAM), Calceta, Manabí, Ecuador. \\ ${ }^{5}$ Western College of Veterinary Medicine, University of Saskatchewan, Saskatoon, SK, Canada.
}

\begin{abstract}
Knowledge of follicular wave dynamics obtained through the use of real-time ultrasonography and the development of the means by which follicular wave dynamics can be controlled have provided practical approaches for the in vivo and in vitro production and transfer of embryos in cattle. The elective control of follicular wave emergence and ovulation has had a great impact on the application of on-farm embryo transfer, especially when large groups of donors need to be superstimulated at the same time. Although estradiol and progestins have been used for many years, practitioners in countries where estradiol cannot be used have turned to alternative treatments, such as mechanical follicle ablation or the administration of GnRH for the synchronization of follicle wave emergence. In vitro embryo production also benefits from the synchronization of follicle wave emergence prior to Cumulus Oocyte Complexes (COCs) recovery. As Bos indicus cattle have high antral follicle population, large numbers of oocytes can be obtained by ovum pick-up (OPU) without superstimulation. However, synchronization of follicular wave emergence and superstimulation is necessary to obtain high numbers of COCs by OPU and blastocysts following in vitro fertilization in Bos taurus donors. Finally, embryos can now be transferred in commercial beef or dairy herds using efficacious synchronization and resynchronization protocols that are easily implemented by farm personnel. These technologies can also be used to resolve reproductive problems such as the reduced fertility observed during summer heat stress and/or in repeat-breeder cows in commercial dairy herds.
\end{abstract}

Keywords: superstimulation, bovine embryos, fixedtime embryo transfer.

\section{Introduction}

The objective of ovarian superstimulatory treatments in cattle is to stimulate the growth of the maximum number of antral follicles that produce competent oocytes (Bó and Mapletoft, 2014). The usual regimen for in vivo embryo production has been twice daily intramuscular (i.m) treatments with FSH for 4 or 5 days (Bó and Mapletoft, 2014). However, previous experiments have indicated that follicle maturation and ovulation rate can be improved in at least some donors if FSH treatments are administered over 6 or 7 days (Bó et al., 2008; García Guerra et al., 2012). For in vitro embryo production (IVP), the requirement of superstimulation with gonadotropins prior to ovum pick-up (OPU) is still under discussion, and the approach may differ depending on whether the donors are of Bos taurus or Bos indicus breedings. Regardless of the method of embryo production, these technologies can be implemented in commercial beef and dairy operations for genetic improvement and even to increase fertility during the summer heat stress and/or in repeat-breeder dairy cows. The objective of this manuscript is to briefly summarize the existing protocols for superstimulating donors for in vivo and in vitro embryo production and to propose alternatives by which embryo transfer technologies can be implemented more widely in commercial herds.

\section{Superstimulation and in vivo embryo production}

Two very important factors influencing variability in superstimulatory response are the intrinsic number of antral follicles in donors, and the stage of follicular development at the beginning of FSH treatments. Response can be predicted by antral follicle count done with ultrasonography (Singh et al., 2004; Ireland et al., 2011), or measurement of circulating concentrations of anti-Müllerian hormone [AMH; Bos taurus (Rico et al., 2012; Monniaux et al., 2013), Bos indicus (Batista et al., 2014)]. High antral follicle counts have resulted in more ovulations and a greater number of transferable embryos following superstimulation with FSH than low antral follicle counts (Ireland et al., 2007). Similarly, the top quartile of circulating AMH values was associated with a greater superovulatory response than the lowest quartile (Souza et al., 2014). Therefore, selection of donors based on antral follicle counts or AMH concentrations may be important for predictable and economical embryo production.

\section{Synchronization of follicle wave emergence for superstimulation}

Transvaginal ultrasound-guided follicle ablation followed by FSH treatments 1 or 2 days later is 
very efficacious in the synchronization of follicle wave emergence (Bergfelt et al., 1997; Baracaldo et al., 2000; Lima et al., 2007), but requires specialized skills to apply in the field. However, if donors are housed in an embryo production facility, follicle aspiration by OPU can be used to obtain COCs for IVP and at the same time synchronize follicle wave emergence for the production of in vivo-derived (IVD) embryos in the same donor (Surjus et al., 2014). The number of embryos produced in that study was higher when the interval from OPU to superstimulation was 2 days rather than 1 day. However, there was a concern that the number of recruited 3 to $5 \mathrm{~mm}$ follicles 2 days after OPU was lower than those counted at the time of OPU itself, which was performed at random stages of the estrous cycle $(15.2 \pm 2.3$ vs $33.7 \pm 2.3$; $\mathrm{P}<0.05$; Surjus et al., 2014). However, a more recent report (Cirit et al., 2019) suggested that this can be overcome using a longer superstimulation treatment (i.e., 6 days) rather than the traditional 4-day FSH protocol. In this study, donors received 400 IU of equine Chorionic Gonadotropin (eCG) 1 day after OPU followed by a 5-day FSH treatment initiated 1 day later (Cirit et al., 2019). However, a critical study with a representative number of animals and an adequate control group is needed to confirm this notion. The practical application of producing embryos in vitro and in vivo in succession in the same donor has important practical implications because it potentially increases the production of embryos in a short period of time.

The preferred approach for synchronization of follicular wave emergence in South America is the administration of $2 \mathrm{mg}$ estradiol benzoate (EB) or $5 \mathrm{mg}$ estradiol-17ß and 50 - $100 \mathrm{mg}$ progesterone (P4) and insertion of P4-releasing device 4 days before initiating FSH treatments (Bó et al., 1996, 2002a; Bó and Mapletoft, 2014). This protocol has been extensively reviewed (Bó and Mapletoft, 2014) and will not be discussed further in this manuscript. However, estradiol is not available in many other countries around the world, requiring the use of alternatives such as follicle ablation or GnRH to synchronize follicle wave emergence prior to superstimulation (reviewed in Bó and Mapletoft, 2014)

Attempts to synchronize follicular wave emergence for superstimulation with GnRH were initially unsuccessful; however, subsequent field data were more promising. In these cases, GnRH was administered 1.5 to 3.0 days after the insertion of an intravaginal P4-device which may have increased the probability of an LH-responsive follicle at the time of treatment with GnRH. Indeed, Bó et al. (2010) reported the strategic use of $\mathrm{PGF}_{2 \alpha}$, a P4-device and $\mathrm{GnRH}$ to induce ovulation prior to initiating $\mathrm{FSH}$ treatments. Basically, a persistent follicle was induced by treatment with $\mathrm{PGF}_{2 \alpha}$ at the time of progestin device insertion; following administration of $\mathrm{GnRH} 7$ days later, ovulation occurred in more than $95 \%$ of the animals. Superstimulation initiated 36 hours after GnRH (with the P4-device remaining in place) resulted in a superovulatory response that did not differ from controls superstimulated on Days 8 to 12 of the estrous cycle. More recently, Hinshaw et al. (2015) reported no difference in superovulatory response whether GnRH was administered 2 or 7 days after insertion of a P4device.

\section{Extended superstimulatory treatment protocols}

An earlier study provided rationale for the hypothesis that superstimulatory treatment may recruit follicles into the wave and allow small follicles to attain medium and large diameters (Adams et al., 1994). Based on this notion, attempts have been made to increase the superovulatory response by adding eCG treatment prior to initiating FSH treatments. Pretreatment with eCG 2 days before the conventional FSH treatment protocol resulted in a numerically greater number of transferable embryos $(6.7 \pm 1.2$ vs $4.9 \pm 0.9)$ in an unselected group of donors (Caccia et al., 2000), and a significantly greater number of transferable embryos in donors that were defined as poor responders (3.6 \pm 0.6 vs $1.0 \pm 0.2$; Bó et al., 2008).

A more recent study evaluated the superovulatory response and embryo recovery in donors treated with either a 4-day or a 7-day FSH treatment protocol utilizing the same total dose of $400 \mathrm{mg} \mathrm{FSH}$ (Folltropin-V; Vetoquinol Inc., Canada) administered twice daily at a constant daily dosage (García Guerra et al., 2012). The mean number of ovulations detected by ultrasonography was greater in the 7-day treatment group $(30.9 \pm 3.9$ vs $18.3 \pm 2.9, \mathrm{P}=0.01)$, consistent with a numerically greater number of follicles $\geq 10 \mathrm{~mm}$ just prior to ovulation $(27.5 \pm 4.1$ vs $19.5 \pm 2.6$; $\mathrm{P}=0.11)$. Moreover, ovulations occurred more synchronously in the 7-day group (93\% of ovulations occurred 12 to 36 hours post-LH as compared to $66 \%$ in the 4-day group) suggesting that the superstimulated follicles were more mature and capable of responding to an $\mathrm{LH}$ stimulus. Although the total number of ova/embryos, fertilized ova and transferable embryos did not differ statistically, all end-points favored the 7-day group. In addition, when data from two cows with fertilization failure were removed, the number of transferable embryos tended to be higher in the 7-day group $(7.6 \pm 1.7 \mathrm{vs}$ $4.2 \pm 1.5 ; \mathrm{P}=0.07)$.

In another study (Dias et al., 2013a), a 7-day superstimulation protocol was used to investigate the influence of $\mathrm{P} 4$ on follicle growth, ovulation and oocyte competence. Beef cows were superstimulated with $25 \mathrm{mg}$ of FSH twice-daily for 4 or 7 days. Again, the superstimulatory response (number of large follicles just prior to insemination) was greater $(\mathrm{P}<0.05)$ in the 7-day group, and the numbers of ovulations (15.4 vs 11.6) and embryos (6.7 vs 5.9) were numerically higher in the 7-day group.

The duration of treatment rather than the FSH dose appears to be responsible for the increase in the superstimulatory response. In the two studies cited above, the number of ovulatory-sized follicles just prior to ovulation was greater following 7 days of superstimulation than 4 days, whether the total dose of FSH was greater (Dias et al., 2013a) or the same (García Guerra et al., 2012). In addition, there was no 
evidence that more follicles were recruited; the total numbers of follicles at the end of FSH treatment was the same as that at the beginning of FSH treatment, the only difference was the distribution of follicle sizes. Furthermore, in a recent study of follicles undergoing a 4-day superstimulation protocol, gene expression in granulosa cells was altered compared to a single, naturally occurring dominant follicle (Dias et al., 2013b, 2014). Expression of growth-related genes similar to the pre-LH stage of follicle growth (even though LH had been administered) and those involved in oxidative stress response were up-regulated in granulosa cells of follicles undergoing a 4-day FSH superstimulation protocol, compared to a preovulatory follicle of an unstimulated follicular wave. Genes related to a disturbance in angiogenesis were also up-regulated in superstimulated follicles. Since the mean growth rate of follicles between initiation of treatment and ovulation was more similar to naturally cycling cattle in the 7-day group than in the 4-day group, we speculate that gene expression during the 7-day superstimulation protocol may be more similar to the naturally occurring single preovulatory follicle.

\section{Use of eCG to replace the last four FSH applications}

In search of possible improvements to the superstimulatory treatment protocol Price et al. (1999) demonstrated that during the superstimulatory treatment, LH pulse frequency diminish shortly after the first FSH injection and are accentuated during the last injections and the preovulatory period. This occurs as a consequence of the high steroidogenic activity and an increase in the concentrations of estradiol in superstimulated cows and may affect superovulatory response and embryo quality (Price et al., 1999). Therefore, a treatment that provides LH support at the end of the superstimulation treatment may be beneficial, since LH has been shown to be essential for the final growth of the superstimulated follicles and for the completion of oocyte maturation (Oliveira et al., 2014).

Equine Chorionic Gonadotropin is a complex glycoprotein that has FSH and LH activity in non-equid species (Murphy and Martinuk, 1991). A remarkable feature of eCG that has been exploited in multiple experimental and commercial contexts is its ability to express FSH and LH activity in the cow (Murphy, 2012). In cattle, this gonadotropin has a prolonged action time, due to the proportion of sialic acid (10 to $15 \%$ ) present in its molecule (Murphy and Martinuk, 1991).

In the early days of bovine embryo transfer, eCG was used to induce superovulation in donors (Bó and Mapletoft, 2014). However, its long half-life, which was a feature for induction of superovulation with a single administration, resulted in multiple unovulated follicles and poor embryo quality at the time of embryo collection (reviewed in Bó and Mapletoft, 2014; Murphy, 2012). More recently, the last two doses of FSH in a superstimulation protocol have been replaced by different dosages of eCG, with the intention of providing more $\mathrm{LH}$ support to the growing follicles (reviewed in Barros et al., 2012). Some studies have shown beneficial effects of the association of FSH and eCG (Cifuentes et al., 2009; Reano et al., 2009; Mattos et al., 2011), whereas others showed no effect (Sartori et al., 2009; Davis et al., 2012).

Although the administration of eCG near the end of the FSH treatment protocol did not always improve the superovulatory response, it was not detrimental and raised some interest in its use to simplify the superstimulation protocol and to decrease the cost of the treatment, since eCG is usually less expensive than the pituitary extracts containing FSH. Therefore, we designed a study to evaluate the superovulatory response and embryo production in beef donors using twice daily FSH injections over 4 days or an alternative protocol in which the last $4 \mathrm{FSH}$ treatments were replaced by a single injection of eCG (Barajas et al., 2019). Twelve (Experiment 1) and 18 (Experiment 2) mature Bonsmara donor cows were superstimulated twice at a 46-day interval in a crossover design. Follicular wave emergence was synchronized by the administration of estradiol-17 $\beta$ at the time of insertion of a P4-device and superstimulation was initiated 4 days later. Donors in the control group received 8 injections of FSH i.m. (total dose: $300 \mathrm{mg}$ ) in a twice-daily decreasing dosage schedule over 4 days, whereas donors in the $\mathrm{FSH}+\mathrm{eCG}$ group received only the first 4 injections of FSH (total dose: $220 \mathrm{mg}$ ) and 48 $\mathrm{h}$ after initiating treatment, 800 IU of eCG i.m. in a single administration. All donors received $\mathrm{PGF}_{2 \alpha}$ i.m. with the eCG administration and again $12 \mathrm{~h}$ later. The P4-devices were removed in the AM of the next day. All cows received GnRH 24 hours after the removal of the P4-device and were inseminated with frozen/thawed semen from two bulls 12 and 24 hours later. Ova/embryos were collected and evaluated according to the IETS standards 7 days after the administration of GnRH. In Experiment 2, donors were treated only with $\mathrm{FSH}+\mathrm{eCG}$. The total dosage of FSH was $200 \mathrm{mg}$ and the dosage of eCG was either 800 or 600 IU. Results of both experiments are presented in Table 1 . In Experiment 1, the FSH (control) group produced a higher $(\mathrm{P}<0.01)$ number of fertilized ova, but there were no differences in the number of transferable embryos. In Experiment 2, no differences were found between the $\mathrm{FSH}+800$ eCG or $\mathrm{FSH}+600$ eCG groups in any of the parameters evaluated. In conclusion, the replacement of the last 4 injections of FSH by a single administration of either 600 IU or 800 IU of eCG decreased the number of FSH treatments required in a superstimulation protocol without adversely affecting the production of transferable embryos. 
Bó et al. In vitro and in vivo embryo production in cattle.

Table 1. Embryo production (means \pm SEM) in Bonsmara donors treated with FSH or FSH+eCG .

\begin{tabular}{lcrrc}
\hline & $\mathrm{n}$ & Total ova/embryos & Fertilized ova & Transferable embryos \\
\hline Experiment 1 & & & & \\
\hline FSH & 12 & $11.7 \pm 2.5$ & $10.5 \pm 2.3^{\mathrm{a}}$ & $5.7 \pm 1.4$ \\
FSH+800 IU eCG & 12 & $9.6 \pm 1.5$ & $6.8 \pm 1.0^{\mathrm{b}}$ & $5.3 \pm 1.0$ \\
\hline Experiment 2 & & & & \\
\hline FSH+800 IU eCG & 18 & $6.7 \pm 0.7$ & $5.4 \pm 0.8$ & $3.6 \pm 0.7$ \\
FSH+600 IU eCG & 18 & $6.1 \pm 1.1$ & $4.3 \pm 1.0$ & $3.7 \pm 0.8$ \\
\hline
\end{tabular}

Different letters $(\mathrm{a}, \mathrm{b})$ within a column indicate significant difference $(\mathrm{P}<0.05) .{ }^{\varepsilon}$ Donors were treated with 8 intramuscular injections of FSH administered at $12 \mathrm{~h}$ intervals (FSH group) or the last 4 FSH treatments were replaced by a single intramuscular injection of eCG (FSH + eCG group).

\section{Manipulation of follicular development for in vitro embryo production (IVP)}

The IVP of embryos, together with the technique of OPU, are reproductive biotechnologies that have advanced greatly in the last 10 years. This technology is highly developed in Brazil, where $57 \%$ of IVP embryos that are transferred in the world are produced (Viana et al., 2018). As indicated earlier, Bos indicus cattle have a higher number of follicles recruited per wave as compared to Bos taurus breeds and this has resulted in the recovery of a higher number of oocytes with OPU (Pontes et al., 2009; Baruselli et al., 2012; Watanabe et al., 2017). Likewise, field data from our laboratory has shown that Brahman-influenced synthetic breeds produce significantly more viable oocytes and transferable blastocysts following OPU/IVF than Bos taurus breeds (Bernal et al., 2016).

Several studies were designed to evaluate the effects of synchronizing follicular wave emergence and superstimulation on the number and quality of the COCs recovered by OPU and submitted to IVP (Ongaratto et al., 2015; Baruselli et al., 2016). The most important conclusions of these studies were: 1) Synchronizing follicle wave emergence prior to OPU increased the number of COCs obtained and blastocysts produced in Bos taurus, but not Bos indicus breeds; 2) Treatment with estradiol and P4 or the removal of the dominant follicle (DFR) were equally efficacious in the synchronization of follicular wave emergence for OPU; 3) Superstimulatory treatment with FSH increased the number and quality of COCs obtained by OPU in Bos taurus breeds, but not in Bos indicus breeds. In an experiment conducted in Brazil with Holstein donors (Vieira et al., 2014), all cows received a P4-device and $2 \mathrm{mg}$ of EB (Day 0). Cows in the control group received no additional treatments, while cows in the FSH-treated group received twice daily treatments on Days 4 and 5 (total dose of $200 \mathrm{mg}$ ). On Day 7, the P4-device device was removed and the OPU was performed (40 $\mathrm{h}$ after the last FSH treatment). There were no differences between groups $(P=0.92)$ in the number of follicles that were aspirated per OPU session (17.2 \pm 1.3 vs $17.1 \pm 1.1$ in the control and FSH-treated cows, respectively); however, COCs from FSH-treated cows yielded a higher blastocyst rate (34.5\%, 89/258 vs 19.8\%, 55/278, $\mathrm{P}<0.001$ ) and more transferable embryos per OPU session than the control group ( $3.0 \pm 0.5$ vs $1.8 \pm 0.4, \mathrm{P}$ $=0.02)$. It was concluded that superstimulation of Holstein donors with FSH before OPU increased the efficiency of IVP by increasing COC and embryo quality. In addition, non-lactating donors had a higher percentage of in vitro blastocyst development and produced more embryos per OPU session than lactating cows. In a later study, similar results were obtained when the four doses of FSH were replaced by a single i.m. injection of $200 \mathrm{mg}$ of FSH diluted in a $0.5 \%$ hyaluronan solution (MAP-5, Vetoquinol; Vieira et al., 2015).

Two other studies were performed in Angus donors. In the first study (Ongaratto et al., 2011), administration of FSH resulted in a higher number of COCs obtained by OPU. In the second study (Ongaratto et al., 2019), multiparous, non-lactating Angus cows, were randomly allocated into two treatment groups and treated twice in a cross-over design. Follicular wave emergence was synchronized with estradiol $17-\beta$ and progesterone, plus a P4-device. Four days later (Day 4) donors received either $160 \mathrm{mg}$ FSH diluted in $4 \mathrm{ml}$ of MAP-5 by a single i.m. injection or no FSH (Control group). COCs were obtained by OPU 72 h later (Day 7). Results are summarized in Table 2. The number of viable COCs was significantly higher in the FSH-treated donors than in controls.

Although administration of FSH prior to OPU has been a common practice for increasing the numbers of follicles available for OPU, most studies have adopted the conventional twice daily treatments with $\mathrm{FSH}$, with either positive results in the number of COCs collected and embryos produced (Ongaratto et al., 2011; Blondin et al., 2012; Vieira et al., 2014; 2015) or no effect on COC or embryo production in Holstein cows (Oliveira et al., 2016). Obviously, the possibility of giving a single FSH injection instead of four prior to OPU in genetically superior animals is critically important for the widespread application of this technology in commercial herds, where personnel are not as familiar with intensive treatment protocols as producers working with purebred cattle. 
Table 2. Mean (+SEM) numbers of total and viable cumulus oocyte complexes (COCs) recovered and number of blastocysts produced following superstimulation in Angus donors ${ }^{£}$.

\begin{tabular}{lccc}
\hline \multirow{2}{*}{ Group } & \multicolumn{2}{c}{ COCs } & Blastocysts \\
\cline { 2 - 4 } & Total & Viable & Total \\
\hline $\begin{array}{l}\text { Single FSH } \\
(\mathrm{n}=9)\end{array}$ & $21.4 \pm 2.4^{\mathrm{a}}$ & $14.1 \pm 1.6^{\mathrm{a}}$ & $4.2 \pm 0.8$ \\
$\begin{array}{l}\text { Control } \\
(\mathrm{n}=9)\end{array}$ & $15.9 \pm 2.7^{\mathrm{b}}$ & $10.6 \pm 2.0^{\mathrm{b}}$ & $2.7 \pm 0.7$ \\
\hline P Value & 0.02 & 0.02 & 0.13 \\
\hline
\end{tabular}

Different letters (a,b) within a column indicate significant difference $(\mathrm{P}<0.05) .{ }^{\varepsilon}$ Donors were treated with $5 \mathrm{mg}$ estradiol 17- $\beta$ and $50 \mathrm{mg}$ of progesterone i.m. plus a P4-device on Day 0, followed by either $160 \mathrm{mg}$ Folltropin-V diluted in $4 \mathrm{ml}$ of MAP-5 by a single i.m. injection (Single FSH group) or no FSH (Control group) on Day 4 . OPU was performed in both groups on Day 7.

\section{Strategies for the application of in vivo and in vitro embryo transfer in commercial operations}

The commercial embryo transfer industry began in North America in the early 1970s, and the technology soon spread to South America (Bó and Mapletoft, 2014). Brazil and Argentina have consistently ranked in the top five countries outside North America and Europe in the production IVD embryos. Viana (2018) has reported recently that more than 992,289 IVP and 495,054 IVD bovine embryos were produced worldwide in 2017. North America accounted for more than 59\% $(292,755)$ of the IVD embryos, while South America only accounted for $10 \%$ $(49,230)$. On the other hand, the distribution of IVP embryos were similar in North $(475,696 ; 48 \%)$ and South (453,685; 46\%) America. This is the first report in which North America produced more IVP than IVD embryos, whereas in South America the number of IVP embryos has been higher than the number of IVD embryos for more than 10 years.

The application of a successful program using IVD or IVP embryos not only relies on a robust IVP system, but also on the implementation of a successful embryo transfer program. Nutrition, management and efficiency in the synchronization of estrus and ovulation are among the factors that affect the use of these technologies (Mapletoft and Bó, 2016). To avoid limitations associated with estrus detection, treatments that synchronize the time of ovulation in recipients, which were developed originally for fixed-time AI (FTAI), have been utilized for fixed-time embryo transfer (FTET; Bó et al., 2002a, 2012a). These treatments are generally divided into those that are GnRH-based (Ambrose et al., 1999) and those that are estradiol-based (Bó et al., 2002) and are selected depending on the availability of the hormones in different countries. In either case, the recipient protocols include the insertion of a P4-device for 7 or 8 days (Hinshaw, 1999; Bó et al., 2002b).

Estradiol and P4- (estradiol/P4) based treatments are the most commonly used protocols to synchronize follicle wave emergence and ovulation of recipients in South America (Baruselli et al., 2010). The simplified protocol used most commonly consists of insertion of a P4-device and the administration of $2 \mathrm{mg}$ EB on Day 0, and $\mathrm{PGF}_{2 \alpha}$ at the time of insertion and removal of the P4-device if it is impregnated with $>1 \mathrm{~g}$ of P4 and only at P4-device removal when it contains $<1 \mathrm{~g}$ of P4. The P4-device is usually removed on Day 7 or 8 and 300 or 400 IU of eCG are administered at that time (Bó et al., 2002a). Ovulation is induced by the administration of 0.5 or $1 \mathrm{mg}$ of estradiol cypionate (ECP) at the time of P4-device removal and all recipients with a corpus luteum (CL) 9 days later receive an embryo (i.e., 7 days after the expected time of estrus; Baruselli et al.. 2010, 2011; Bó et al., 2012b). Overall, 75 to 85\% of the recipients treated with this protocol receive an embryo; P4 concentrations are high at the time of embryo transfer and pregnancy per embryo transfer (P/ET) range from 40 to $60 \%$, when both embryos and recipients are of high quality (reviewed in Bó et al., 2002a; Baruselli et al., 2010, 2011).

Recent studies have suggested that increasing the interval from P4-device removal to FTAI may improve pregnancy per $\mathrm{AI}(\mathrm{P} / \mathrm{AI})$ in a GnRH-based protocol (named 5-day CoSynch+CIDR) (Bridges et al., 2008) or estradiol/P4-based treatments (named J-Synch protocol; Bó et al., 2016). In both protocols, a second $\mathrm{GnRH}$ is administered 72 hours after the removal of the P4-device (prolonged proestrus). The benefits associated with the prolonged proestrus were a prolonged exposure to estradiol prior to ovulation and an increased ability of the uterus to support embryo development (reviewed in Bó and Cedeño, 2018).

Using a modified 5-day CoSynch+CIDR protocol (no GnRH at P4-device insertion, a single injection of PGF2 $\alpha$ at P4 removal on Day 5 and GnRH on Day 8), Sala et al. (2016) reported similar P/ET rates with IVP embryos as in recipients synchronized with two PGF $2 \alpha$ treatments 14 days apart and estrus detection. Furthermore, Menchaca et al. (2015, 2016) reported higher pregnancy rates in beef recipients receiving Holstein IVP embryos and synchronized with the J-Synch protocol as compared to the conventional estradiol/P4 protocol in which ECP was given at P4device removal. Although embryos can be transferred at a fixed time, without estrus observation, optimal P/ET and calving rates were obtained when tail paint was used to detect estrus and only recipients with their tail paint rubbed-off (i.e., in estrus) received embryos 7 days later (reviewed in Bó and Cedeño, 2018). The recommended protocols for FTET in recipients are shown in Figure 1. 
(A)

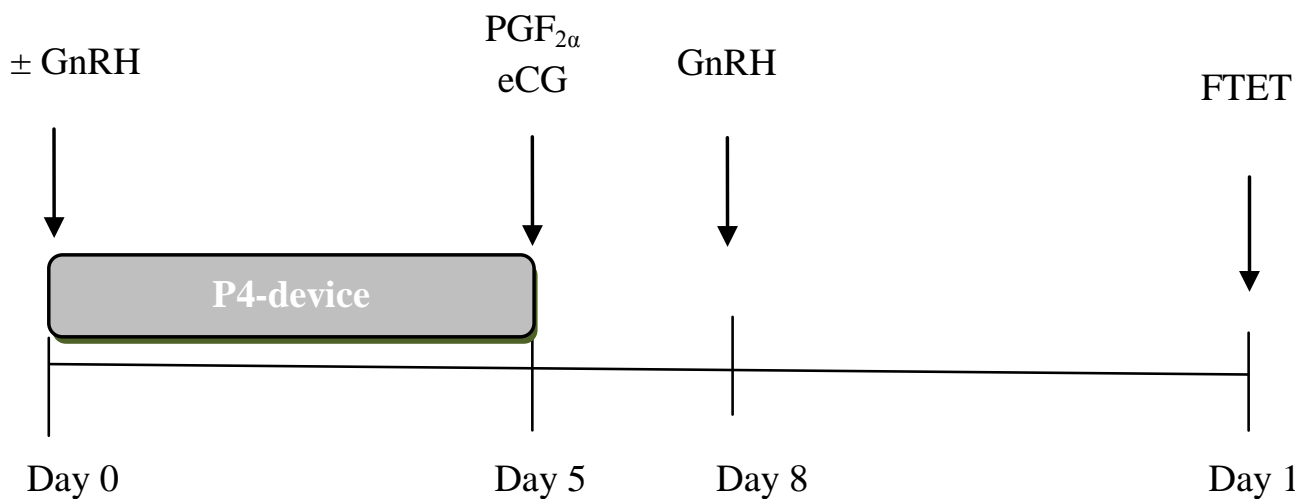

$\begin{array}{llll}\text { Day } 0 & \text { Day } 5 & \text { Day } 8 & \text { Day } 15\end{array}$

(B)

$2 \mathrm{mg}$ EB $\quad \begin{array}{cc}\mathrm{PGF}_{2 \alpha} \\ \mathrm{eCG}\end{array}$

FTET

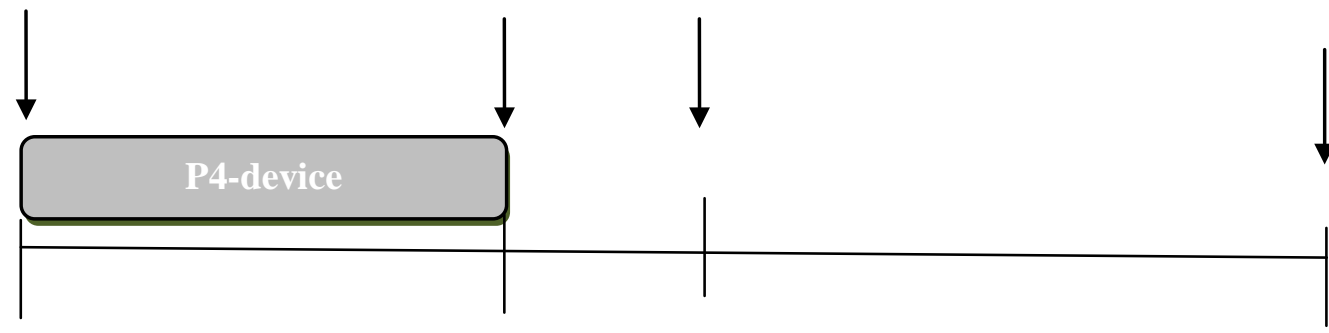

$\begin{array}{llll}\text { Day } 0 & \text { Day } 6 & \text { Day } 9 & \text { Day } 16\end{array}$

(C)

$2 \mathrm{mg}$ EB

$\mathrm{PGF}_{2 \alpha}$

eCG

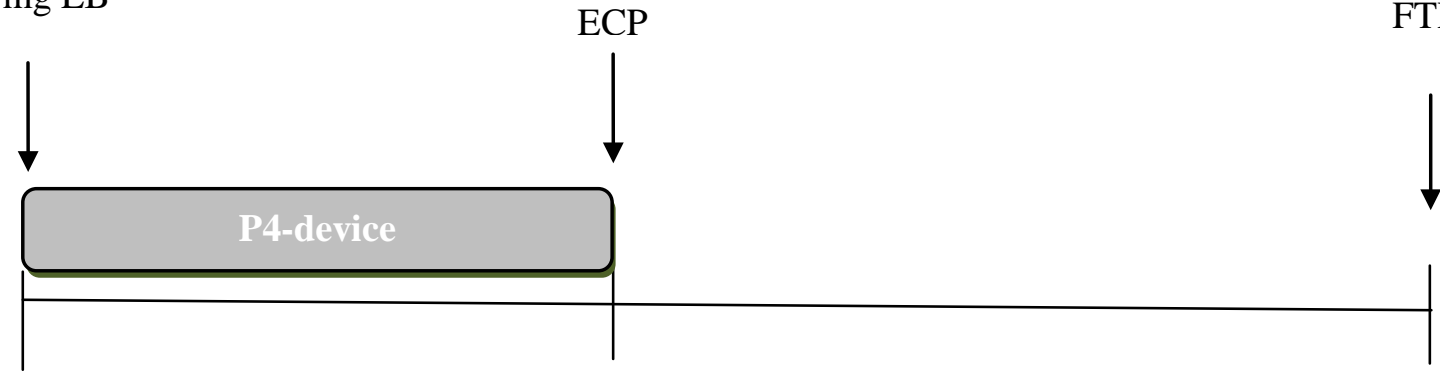

Day 0

Day 8

Day 17

Figure 1. Recommended protocols for FTET in bovine recipients. A) Modified 5-day GnRH+P4 device protocol (P4 device on Day 0, PGF2 $\alpha$ and eCG on Day 5 and GnRH on Day 8). B) J- Synch protocol (P4 device and EB on Day 0 , PGF2 $\alpha$ and eCG on Day 6 and GnRH on Day 9). C) Conventional ECP protocol (P4 device and EB on Day 0, PGF2 $\alpha$, eCG and ECP on Day 8) If estrus detection is implemented with tail patches or tail paint, recipients are observed $72 \mathrm{~h}$ after P4 device removal in protocols A and B and $54 \mathrm{~h}$ after P4 removal on protocol B.

\section{Embryo Transfer in commercial beef herds}

Although the numbers of embryos produced have increased over the years in several regions of the world (Viana, 2018), the main bottleneck for the widespread application of this technology has been the availability of recipients and the intensive management needed for embryo transfer in commercial herds. This problem has been changing as a consequence of the widespread application of successful FTAI in commercial herds. Therefore, in farms where personnel are already familiar with the application of synchronization and re-synchronization of ovulation for FTAI, the application of an embryo transfer program with the normal management of the cow herd seems feasible. Lactating cows and heifers can be synchronized at the beginning of the breeding season to receive IVD or IVP embryos and then resynchronized and inseminated or just simply exposed to clean-up bulls during the remainder of the breeding season. 
A study was designed to examine pregnancy rates in Bos indicus cows that were synchronized for FTAI or FTET at the beginning of the breeding season (Martins et al., 2014). In this experiment, 634 lactating Nelore cows were randomly assigned to one of four treatment groups: 2 FTAI $(n=160), 2$ FTET $(n=152), 1$ FTAI followed by 1 FTET (FTAI/FTET; $n=160)$ and 1 FTET followed by 1 FTAI (FTET/FTAI; $n=158$ ). All animals were treated with a P4-device for 8 days, EB on Day 0 , and $\mathrm{PGF}_{2 \alpha}$, eCG and ECP on Day 8. Cows undergoing FTAI were inseminated $48 \mathrm{~h}$ after P4-device removal, whereas those receiving embryos were evaluated for the presence of CL 9 days after P4-device removal and those with a CL received IVP embryos. Cows in both groups were resynchronized using the same protocol that was used for the first service, 30 days after the first FTAI or 23 days after FTET. The post-partum period at the times of first service was 41.4 days for FTAI and 47.4 days for FTET and 82.8 days for FTAI and 89.8 days for FTET for the second service. Pregnancy diagnosis was performed by ultrasonography at 30 and 60 days of gestation. Pregnancy rates after the first service were higher $(\mathrm{P}<0.01)$ in cows that were FTAI $(59.4 \%$ and $59.4 \%$ for 2 FTAI and FTAI/FTET group respectively) than those that were FTET (31.7\% and $32.7 \%$ for 2 FTET and FTET/FTAI groups, respectively). Similarly, pregnancy rates after the second service also differed $(\mathrm{P}=0.06)$ among groups: 2 FTAI (50.8\%), FTAI/FTET (40.6\%) FTET/FTAI (51.9\%) and 2 FTET (35.0\%). Finally, the cumulative pregnancy rate (first + second service) was higher in the groups that receive 2 FTAI (80.0\%) than those receiving 2 FTET (55.8\%); pregnancy rates in the other groups that received the combined techniques were intermediate and did not differ (FTAI/FTET: $\quad 75.6 \%$ and FTET/FTAI: $66.5 \%$, respectively). The conclusion of this study was that although the use of two consecutive FTET had a lower cumulative pregnancy rate than two consecutive FTAI, the association between FTAI and FTET programs can be considered as an alternate strategy to increase number of offspring from embryo transfer.
Other approaches have been implemented in the field. In one study (Bó, personal communication), an embryo transfer program was implemented in an extensive Hereford herd in Southern Argentina. In this herd, cows were synchronized with a conventional estradiol/P4-based synchronization protocol for FTET $(\mathrm{n}=62)$ or were FTAI at the beginning of the breeding season $(n=300)$. In the FTET 49 cows $(79.0 \%)$ had CL 9 days after P4-device removal and received IVD frozen/thawed embryos. The day after FTET all cows were exposed to clean up bulls for the remaining of the breeding season. Twenty cows (40.8\%), were pregnant following FTET and the pregnancy rate to FTAI was $54 \%(162 / 300 ; \mathrm{P}<0.05)$. However, the overall pregnancy rate at the end of the breeding season was $91.0 \%$ and did not differ among groups.

These previous studies are examples of the many approaches that can be implemented using FTAI and FTET in commercial beef herds. Most of the protocols were designed for synchronization and resynchronization and have been published elsewhere (for recent reviews see Bó et al., 2016 and Baruselli et al., 2017). Two of the protocols for re-synchronization are called Resynch 22 and Resynch 14 (Baruselli et al., 2017). In the Resynch 22, cows receive $2 \mathrm{mg} \mathrm{EB}$ and heifers $1 \mathrm{mg} \mathrm{EB}$ at P4-device insertion on Day 22 after FTAI. Pregnancy diagnosis is performed at device removal (Day 30) and non-pregnant animals receive $\mathrm{PGF}_{2 \alpha}$ and ECP and are inseminated on Day 32. The Resynch 14 protocol involves the use of color Doppler ultrasonography for the detection of pregnancy based on the vascularization and size of the CL on Day 22 after the first AI. The resynchronization treatment starts 14 days after FTAI with the re-insertion of a used P4device and the administration of $100 \mathrm{mg}$ P4 IM (Rezende et al., 2016) at the same time. Cows are scanned with Doppler ultrasonography for pregnancy at P4-device removal (Day 22) and non-pregnant animals receive $\mathrm{PGF}_{2 \alpha}$ and ECP and are inseminated on Day 24. A proposed program using FTET and Resynch 22 for FTAI is illustrated in Figure 2.
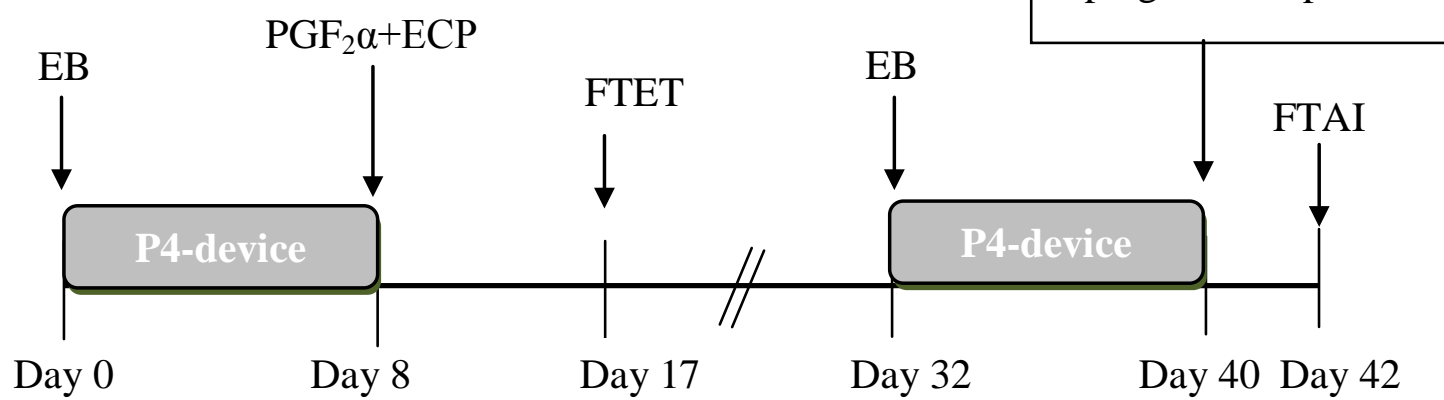

Figure 2. Simple proposal for FTET and resynchronization with FTAI in beef cattle. All cows treated on Day 0 (transferred or not on Day 17) are resynchronized on Day 32. All those recipients not pregnant by Day 30 of gestation (Day 40 of this protocol) are FTAI two days later. 


\section{Use of embryo transfer in dairy herds}

Traditionally, embryo transfer has been implemented in dairy herds to reproduce animals of high genetic merit, but it has also been shown to improve the reproductive performance of high producing commercial herds. The main reason for the potential improvement is the higher fertility reported after embryo transfer in cows experiencing heat stress (Putney et al., 1989; Ambrose et al., 1999; Rodrigues et al., 2004, 2007a, 2007b; 2011; Baruselli et al., 2010) and those diagnosed as repeatbreeders (Rodrigues et al., 2007b; 2010; Dochi et al., 2008; Ferreira et al., 2011; Stewart et al., 2011). In a retrospective study that was performed using lactating Holstein cows, conception rates were higher across the year in cows receiving embryos as compared to those that were AI, but the differences were more pronounced in the warmer months of the year (November through April in the southern hemisphere) (Rodrigues et al., 2007a). In a subsequent study, embryonic loss between 30 and 60 days of pregnancy was also compared retrospectively in lactating Holstein cows subjected to AI or embryo transfer during summer and winter months (reviewed by Baruselli et al., 2011). Although pregnancy loss was higher for embryo transfer than for AI, cows receiving embryos had higher pregnancy rates after 60 days than those that were AI. Therefore, a useful management tool to maintain high pregnancy rates throughout the year would be to produce embryos during the cooler months and use them in embryo transfer during the periods of heat stress.

Another alternative that has tremendous application is to use embryos in repeat breeder cows. Repeat breeder cows are usually defined as cows that do not become pregnant over a period of time (usually after 3 or 4 unsuccessful breedings) that do not have any apparent abnormality that can be diagnosed by a veterinary examination. In a recent study, the transfer of embryos to repeat breeders resulted in increased pregnancy rates compared to AI, without differences in embryo/fetal losses between 30 and 60 days (Ferreira et al., 2010). In another retrospective study (Rodrigues et al., 2007b), conception rates in repeat breeder Holstein cows were greater after transfer of IVD embryos (41.7\%; 1609/3858) than after AI (17.9\%; 1019/5693), supporting the notion that the fertility problem in some repeatbreeders may be associated with oocyte quality and/or failure of early embryo development. Other reports have also shown significant improvements in pregnancy rates using IVD (Son et al., 2007; Dochi et al., 2008) or IVP embryos (Block et al., 2010) in repeat breeder cows. The strategy that will have the greatest impact on the fertility of the herd is to use FTET (without estrus detection; Rodrigues et al., 2010) and IVP or IVD embryos produced with sexed semen, to increase the number of female calves born in the herd. Certainly, IVP is an efficient method for using sexed semen (Wheeler et al., 2006; Pontes et al., 2010; Rasmussen et al., 2013; Pellegrino et al., 2016) and multiple embryos can be produced using a single straw of semen.

\section{Concluding remarks}

The use of protocols that control follicular development and ovulation have the advantage of allowing the widespread application of assisted reproductive technologies. The treatments used to synchronize follicle wave emergence for superovulation by many practitioners around the world have proven to be practical and easy to perform by field staff. Lengthened the superstimulation protocol is also an interesting alternative to produce embryos in vivo, especially in cows with reduced antral follicle populations, because the time necessary for all growing follicles to acquire the ability to ovulate is extended. With respect to the IVP of embryos, cattle with Bos indicus influence adapt very well to this technology because they have a high antral follicle population and, consequently, more COCs are obtained by OPU than in Bos taurus breeds. In Bos taurus donors, synchronization of follicular wave emergence and the use of FSH have resulted in a greater number of COCs per OPU and the IVP of a higher percentage of blastocysts. Nowadays in vitro and in vivo production of embryos can be combined with efficient synchronization and FTET programs that are easily implemented in the field and permit the inclusion of commercial beef herds in embryo transfer programs, combined with FTAI or simply with clean-up bulls. Although the embryo transfer technology has been used in dairy herds for many years, primarily for genetic improvement in a limited number of cows the technology can now be used to resolve reproductive problems such as the reduced fertility observed during the summer months and in repeat breeder cows.

\section{Author contributions}

GAB: Funding Acquisition, Writing - original draft, Supervision, Methology, Investigation, Writing review \& editing; AVC: Investigation, Formal Analysis; RJM: Data Curation, Writing - review \& editing.

\section{Conflict of interest}

The authors have no conflicts of interest in relation to the data published in the present manuscript.

\section{Acknowledgments and Funding disclosure statement}

Research was supported by Fondo Nacional de Ciencia y Tecnología (FONCYT PICT 20174550) GAB; Instituto de Investigación Universidad Nacional de Villa María (UNVM, Programa Aplicación de Biotecnologías Reproductivas para Mejorar la Fertilidad en el Ganado Bovino de Carne y Leche) GAB; Instituto de Reproducción Animal de Córdoba (IRAC) GAB (Research funding), AVC (Scholarship), and Vetoquinol Canada GAB, RJM (Research funding, Folltropin-V); We also thank our colleagues at IRAC and UNVM for technical assistance. GAB, ACV, RJM. 


\section{References}

Adams GP. 1994. Control of ovarian follicular wave dynamics in cattle Implications for synchronization and superstimulation. Theriogenology, 4:19-24.

Ambrose JD, Drost RL, Monson RL, Rutledge JJ, Leibfried-Rutledge ML, Thatcher MJ, Kassa T, Binelli M, Hansen PJ, Chenoweth PJ, Thatcher WW. 1999. Efficacy of timed embryo transfer with fresh and frozen in vitro-produced embryos to increase pregnancy rates in heat-stressed dairy cattle. J Dairy Sci, 82:2369-2376.

Baracaldo MI, Martínez M, Adams GP, Mapletoft RJ. 2000. Superovulatory response following transvaginal follicle ablation in cattle. Theriogenology, 53:1239-1250.

Barajas JL, Cedeño A, Andrada S, Ortega J., Oviedo JM., Tribulo A, Tribulo R, Tribulo H, Bó GA. 2019. Embryo production using follicle stimulating hormone (FSH) or FSH + equine chorionic gonadotropin in beef donors. Reprod Fertil Dev, 31:223. (Abstract).

Barros CM, Satrapa RA, Castilho ACS, Fontes PK, Razza EM, Ereno RL, Nogueira MFG. 2012. Effect of superstimulatory treatments on the expression of genes related to ovulatory capacity, oocyte competence and embryo development in cattle. Reprod Fertil Dev, 25:17-25.

Baruselli PS, Ferreira RM, Sá Filho MF, Nasser LFT, Rodrigues C, Bó GA. 2010. Bovine embryo transfer recipient synchronisation and management in tropical environments. Reprod Fertil Dev, 22:67-74.

Baruselli PS, Ferreira RM, Sales JNS, Gimenes LU, Sá Filho MF, Martins CM, Rodrigues CA, Bó GA. 2011. Timed embryo transfer programs for management of donor and recipient cattle. Theriogenology, 76:15831593.

Baruselli PS, Sá Filho MF, Ferreira RM, Sales JNS, Gimenes LU, Vieira LM, Mendanha MF, Bó GA. 2012. Manipulation of follicle development to ensure optimal oocyte quality and conception rates in cattle. Reprod Dom Anim, 47(Suppl. 4):134-141.

Baruselli PS, Batista EOS, Vieira LM, Ferreira RM, Guerreiro BG, Bayeux BM, Sales JNS, Souza A, Gimenes L. 2016. Factors that interfere with oocyte quality for in vitro production of cattle embryos: effects of different developmental \& reproductive stages. Anim Reprod, 13:264-272.

Baruselli PS, Ferreira RM, Colli MHA, Elliff FM, Sá Filho MF, Vieira L, Gonzales de Freitas B. 2017. Timed artificial insemination: current challenges and recent advances in reproductive efficiency in beef and dairy herds in Brazil. Anim Reprod, 14:558-571.

Batista EOS, Macedo GG, Sala RV, Ortolan MDDV, Sa Filho MF, Del Valle TA, Jesus EF, Lopes RNVR, Renno FP, Baruselli PS. 2014. Plasma antimullerian hormone as a predictor of ovarian antral follicular population in Bos indicus (Nelore) and Bos taurus (Holstein) heifers. Reprod Dom Anim, 49:448-452.

Bergfelt DR, Bó GA, Mapletoft RJ, Adams GP. 1997. Superovulatory response following ablation-induced follicular wave emergence at random stages of the estrous cycle in cattle. Anim Reprod Sci, 49:1-12.
Bernal B, Revol J, Oviedo JM, Tribulo A, Tribulo H, Moreira G, Bó GA. 2016. Influence of breed and season on in vitro embryo production. Reprod Fertil Dev 28, 255-255. (Abstract).

Block J, Bonilla L, Hansen PJ. 2010. Efficacy of in vitro embryo transfer in lactating dairy cows using fresh or vitrified embryos produced in a novel embryo culture medium. J Dairy Sci, 93:5234-5242.

Blondin P, Vigneault C, Nivet AL, Sirard MA. 2012. Improving oocyte quality in cows and heifers - What have we learned so far? Anim Reprod, 9:281-289.

Bó GA, Adams GP, Pierson RA, Mapletoft RJ. 1996. Effect of progestogen plus E-17ß treatment on superovulatory response in beef cattle. Theriogenology, 45:897-910.

Bó GA., Baruselli PS, Moreno D, Cutaia L, Caccia M, Tríbulo R, Tríbulo H, Mapletoft R.J. 2002a. The control of follicular wave development for self-pointed embryo transfer programs in cattle. Theriogenology, 57:53-72

Bó GA, Cutaia L, Tríbulo R. 2002b. Tratamientos hormonales para inseminación artificial a tiempo fijo en bovinos para carne: algunas experiencias realizadas en Argentina. Segunda parte. Taurus, 15:17-32.

Bó GA, Carballo Guerrero D, Adams GP. 2008. Alternative approaches to setting up donor cows for superstimulation. Theriogenology, 69:81-7.

Bó GA, Carballo Guerrero D, Tríbulo A, Tríbulo H, Tríbulo R, Rogan D, Mapletoft R. 2010. New approaches to superovulation in the cow. Reprod Fertil Dev, 22:106-112.

Bó GA, Baruselli PS, Mapletoft RJ. 2012a. Increasing pregnancies following synchronization of bovine recipients. Anim Reprod, 9:312-317.

Bó GA, Peres LC, Cutaia LE, Pincinato D, Baruselli PS, Mapletoft RJ. 2012b. Treatments for the synchronization of bovine recipients for fixed-time embryo transfer and improvement of pregnancy rates. Reprod Fertil Dev, 24:272-277.

Bó GA, Mapletoft RJ. 2014. Historical perspectives and recent research on superovulation in cattle. Theriogenology, 81:38-48.

Bó GA, de la Mata JJ, Baruselli PS, Menchaca A. 2016. Alternative programs for synchronizing and resynchronizing ovulation in beef cattle. Theriogenology, 86:388-396.

Bó GA, Cedeño A. 2018. Expression of estrus as a relevant factor in fixed-time embryo transfer programs using estradiol/progesterone-based protocols in cattle. Anim Reprod, 15:224-230.

Bridges GA, Helser LA, Grum DE, Mussard ML, Gasser CL, Day ML. 2008. Decreasing the interval between GnRH and PGF2 $\alpha$ from 7 to 5 days and lengthening proestrus increases timed-AI pregnancy rates in beef cows. Theriogenology, 69:843-851.

Caccia M, Tríbulo R, Tríbulo H, Bó GA. 2000. Effect of eCG pretreatment on superovulatory response in CIDR-B treated beef cattle. Theriogenology, 53:495. (Abstract).

Cifuentes E, Quevedo L, Hoyos A, Carballo D, Piccardi M, Bó GA. 2009. Efecto de la aplicación de eCG en vacas donantes de embriones superovuladas con 
Folltropin-V. VIII Simposio Internacional de Reproducción Bovina, Córdoba, Argentina, 26, 27 y 28 de Septiembre 2009, pp.7-9 (Abstract).

Cirit Ü, Özmen MF, Küçükaslan I, Köse M, Çınar EM. Kutsal HG, Çinarc EM. 2019. Effect of the interval from follicle aspiration to initiation of lengthened FSH treatment on follicular superstimulatory and superovulatory responses and embryo production in lactating Simmental cows. Theriogenology, 128:218-224. Davis RL, Arteaga A, Hasler JF. 2012. Addition of equine chorionic gonadotropin to a traditional follicle stimulating hormone protocol for superovulation of Bos taurus beef cows. Reprod Fertil Dev, 24:224-225. (Abstract).

Dias FCF, Dadarwal D, Adams GP, Mrigank H, Mapletoft RJ, Singh J. 2013a. Length of the follicular growing phase and oocyte competence in beef heifers. Theriogenology, 79:1177-1183.

Dias FCF, Khan MIR, Sirard MA, Adams GP, Singh J. 2013b. Differential gene expression of granulosa cells after ovarian superstimulation in beef cattle. Reproduction, 146:181-191.

Dias FCF, Khan MIR, Adams GP, Sirard MA, Singh J. 2014. Granulosa cell function and oocyte competence: Super-follicles, super-moms and superstimulation in cattle. Anim Reprod Sci, 149:80-89.

Dochi O, Takahashi K, Hirai T, Hayakawa H, Tanisawa M, Yamamoto Y, Koyama H. 2008. The use of embryo transfers to produce pregnancies in repeatbreeding dairy cattle. Theriogenology, 69:124-128.

García Guerra A, Tribulo A, Yapura J, Singh J, Mapletoft RJ. 2012. Lengthening the superstimulatory treatment protocol increases ovarian response and number of transferable embryos in beef cows. Theriogenology, 78:353-60.

Hinshaw RH. 1999. Formulating ET contracts. In "Proceedings Annual Meeting Soc. for Theriogenology", Nashville, USA. Society for Theriogenology: USA. pp.399-404.

Hinshaw RH, Switzer ML, Mapletoft RJ, Bó GA. 2015. A comparison of 2 approaches for the use of $\mathrm{GnRH}$ to synchronize follicle wave emergence for superovulation. Reprod Fertil Dev, 27:263. (Aabstract).

Ireland JJ, Ward F, Jimenez-Krassel F, Ireland JL, Smith GW, Lonergan P, Evans ACO. 2007. Follicle numbers are highly repeatable within individual animals but are inversely correlated with FSH concentrations and the proportion of good-quality embryos after ovarian stimulation in cattle. Hum Reprod, 22:1687-1695.

Lima WM, Vieira AD, Thaller Neto A, Mezzalira A, Matos RC, Gregory RM. 2007. Improved superovulatory response in beef cattle following ovarian follicular ablation using a simplified transvaginal device. Anim Reprod Sci,100:364-370.

Menchaca A, Dutra S, Carrau JM, Sapriza F, Salazar J, de la Mata JJ, Bó GA. 2015. Improvement of pregnancy rate by using the 6-day J-Synch protocol in recipient cows transferred with in vitro produced embryos. Anim Reprod, 12, 651. (Abstract).

Menchaca A, Dutra S, Carrau JM, Sapriza F, Bó GA. 2016. Improvements of the 423 new J-Synch protocol used for fixed-time embryo transfer (FTET) in recipients transferred with in vitro produced embryos. In: International Congress on Animal Reproduction (ICAR 2016), 18 th, Tours, France, pp.506. (Abstract).

Ireland JJ, Smith GW, Scheetz D, Jimenez-Krassel F, Folger JK, Ireland JLH, Mossa F, Lonergan P, Evans ACO. 2011. Does size matter in females? An overview of the impact of the high variation in the ovarian reserve on ovarian function and fertility, utility of anti-Mullerian hormone as a diagnostic marker for fertility and causes of variation in the ovarian reserve in cattle. Reprod Fertil Dev, 23:1-14.

Ferreira RM, Ayres H, Chiaratti MR, Rodrigues CA, Freitas BG, Meirelles F., Rodrigues CA, Baruselli PS. 2010. Heat stress and embryo production in high-producing dairy cows. Acta Scientiae Veterinariae, pp. s277-s315.

Ferreira RM, Ayres H, Chiaratti, MR, Ferraz ML, Araújo AB, Rodrigues CA, Watanabe YF, Vireque AA, Joaquim DC, Smith LC, Meirelles FV, Baruselli PS. 2011. The low fertility of repeat-breeder cows during summer heat stress is related to a low oocyte competence to develop into blastocysts. J Dairy Sci, 94:2383-2392.

Martins CM, Reis PO, Vieira JH, Soares JG, Vieira LM, Sa Filho MF, Baruselli PS. 2014. Effect of association of FTET and TAI in reproductive programs of Nelore females. Anim Reprod, 11:347. (Abstract).

Mapletoft RJ, Bó GA. 2016. Bovine embryo transfer. In: International Veterinary Information Service (Ed.). IVIS Reviews in Veterinary Medicine. Ithaca: International Veterinary Information Service. (www.ivis.org; Document No. R0104.1106S).

Mattos MC, Bastos MR, Guardieiro MM, Carvalho JO, Franco MM, Mourão GB, Barros CM, 2011. Improvement of embryo production by the replacement of the last two doses of porcine follicle-stimulating hormone with equine chorionic gonadotropin in Sindhi donors. Anim Reprod Sci, 125:119-123.

Monniaux D, Drouilhet L, Rico C, Estienne A, Jarrier P, Touzé JL, Sapa J, Phocas F, Dupont J, Dalbies-Tran R, Fabre S. 2013. Regulation of antiMullerian hormone production in domestic animals. Reprod Fertil Dev, 25:1-16.

Murphy BD, Martinuk SD. 1991. Equine chorionic gonadotrophin. Endocrine Reviews 12:27-44.

Murphy BD. 2012. Equine chorionic gonadotropin: an enigmatic but essential tool. Anim Reprod, 9:223-230.

Oliveira ACS, Mattos MCC, Bastos MR, Trinca LA, Razza EM, Satrapa RA, Sartori R, Barros CM. 2014. Efficiency of superstimulatory protocol P-36 associated with the administration of $\mathrm{eCH}$ and $\mathrm{LH}$ in Nelore cows. Theriogenology, 82:715-719.

Oliveira LH, Sanches CP, Seddon AS, Veras MB, Lima FA, Monteiro PLJ Jr, Wiltbank MC, Sartori R. 2016. Short communication: Follicle superstimulation before ovum pick-up for in vitro embryo production in Holstein cows. J Dairy Sci, 99:9307-9312.

Ongaratto FL, Tribulo A, Ramos M, Rodríguez P, Bó GA. 2011. Oocyte recovery rates and in vitro blastocyst production in cattle treated with a single injection of folltropin-v diluted in a slow-release 
formulation. Repro Fert Dev, 23 (1): 202-203

Ongaratto FL, Rodriguez VP, Tribulo A, Bó GA. 2015. Effect of follicle wave synchronization and gonadotropin treatments on the number and quality of cumulus-oocyte complex obtained by ultrasound-guided ovum pick-up in beef cattle. Anim Reprod, 12:876-883.

Ongaratto FL, Cedeño AV, Rodriguez VP, Tribulo A, Bó GA. 2019. Effect of FSH treatment on cumulus oocyte complex recovery by ovum pick up and in vitro embryo production in beef donor cows. Anim Prod Sci, (Submitted).

Pellegrino CA, Morotti F, Untura RM, Pontes JH, Pellegrino MF, Campolina JP, Seneda MM, Barbosa FA, Henry M. 2016. Use of sexed sorted semen for fixed-time artificial insemination or fixed-time embryo transfer of in vitro-produced embryos in cattle. Theriogenology, 86:888-893.

Pontes JHF, Nonato-Junior I, Sanches BV, ErenoJunior JC, Uvo S, Barreiros TRR, Oliveira JA, Hasler JF, Seneda MM. 2009. Comparison of embryo yield and pregnancy rate between in vivo and in vitro methods in the same Nelore (Bos indicus) donor cows. Theriogenology, 71:690-697.

Pontes JH, Silva KC, Basso AC, Rigo AG, Ferreira CR, Santos GM, Sanches BV, Porcionato JP, Vieira PH, Faifer FS, Sterza FA, Schenk JL, Seneda MM. 2010. Large-scale in vitro embryo production and pregnancy rates from Bos taurus, Bos indicus, and indicus-taurus dairy cows using sexed sperm. Theriogenology, 74:1349-1355.

Price CA, Carriére PD, Gosselin N, Kohram H, Guilbault LA. 1999. Effects of superovulation on endogenous LH secretion in cattle, and consequences for embryo production. Theriogenology, 51:37-46.

Putney DJ, Drost M, Thatcher WW. 1989. Influence of summer heat stress on pregnancy rates of lactating dairy cattle following embryo transfer or artificial insemination. Theriogenology, 31:765-78.

Rasmussen S, Block J, Seidel GE Jr, Brink Z, McSweeney K, Farin PW, Bonilla L, Hansen PJ. 2013. Pregnancy rates of lactating cows after transfer of in vitro produced embryos using $\mathrm{X}$-sorted sperm. Theriogenology, 79:453-461.

Reano I, Carballo D, Tribulo A, Tribulo P, Balla E, Bó GA. 2009. Efecto de la adición de eCG a los tratamientos superovulatorios con Folltropin-V en la producción de embriones de donantes de embriones. In: VIII Simposio Internacional de Reproducción AnimalIRAC, 10th to 12th July de 2009, Córdoba. Argentina, pp.54. (Abstract).

Rezende RG, Freitas BG, Mingoti RD, Colli MHA, Carvalho JBP, Sá Filho MF, Motta JCL, Macedo GG, Baruselli PS. 2016. Follicular dynamics of Nelore cows submitted to resynchronization 14 days after TAI using injectable $\mathrm{P} 4$ for synchronization of follicular wave. Anim Reprod, 13:375. (Abstract).

Rico C, Drouilhet L, Salvetti P, Dalbie`s-Tran R, Jarrier P, Touze' J-L, Pillet E, Ponsart C, Fabre S, Monniaux D. 2012. Determination of anti-Mullerian hormone concentrations in blood as a tool to select Holstein donor cows for embryo production: from the laboratory to the farm. Reprod Fertil Dev, 24:932-944.
Rodrigues CA, Ayres H, Nichi M, Bó GA, Baruselli PS. 2004. Artificial insemination and embryo transfer pregnancy rates in high production Holstein breeding under tropical conditions. Anim Reprod, 14:396. (Abstract).

Rodrigues CA, Ayres H, Ferreira RM, Teixeira AA, Mancilha RF, Oliveira MEF, Souza AH, Baruselli PS. 2007a. Conception rate after artificial insemination and embryo transfer in high producing holstein cows. Acta Sci Vet, 33:1254. (Abstract).

Rodrigues CA, Ayres H, Ferreira RM, Teixeira AA, Mancilha RF, Oliveira MEF, Souza AH, Baruselli PS. 2007b. Comparison of pregnancy rates after artificial insemination or embryo transfer in high producing repeat breeder Holstein cows. Acta Sci Vet, 35:1255. (Abstract).

Rodrigues CA, Teixeira AA, Ferreira RM, Ayres H, Mancilha RF, Souza AH, Baruselli P.S. 2010. Effect of fixed-time embryo transfer on reproductive efficiency in high-producing repeat-breeder Holstein cows. Anim Reprod Sci, 118:110-117.

Rodrigues CA, Ferreira RM, Vieira LM, Ranieri AL, Silva PRL, Baruselli PS. 2011. How FTAI and FTET impact reproductive efficiency of Brazilian dairy herds. Acta Sci Vet, 39:3-13.

Sartori R, Guardieiro MM, Barros CM, Bastos MR, Machado GM, Leme LO, Rumpf R. 2009. Lack of improvement on embryo production by the replacement of the last two doses of pFSH by eCG in superovulated Nelore heifers. Reprod Fertil Dev, 21:245. (Abstract).

Sala RV, Carrenho-Sala LC, Fosado M, Tosta LC, Tosta RD, Stoll M, Moreno JF, Monteiro BM, Baruselli PS, Garcia-Guera A, Wiltbank M. 2016. Comparison of methods for synchronizing recipients of in vitro produced embryos. Reprod Fertil Dev, 28:185185. (Abstract).

Singh J, Domınguez M, Jaiswal R, Adams GP. 2004. A simple ultrasound test to predict the superstimulatory response in cattle. Theriogenology, 62:227-243.

Son DS, Choe CY, Cho SR, Choi SH, Kim HJ, Hur TY, Jung YG, Kang HG, Kim IM. 2007. A CIDRbased timed embryo transfer protocol increases the pregnancy rate of lactating repeat breeder dairy cows. $J$ Reprod Dev, 53:1313-18.

Souza AH, Carvalho PD, Rozner AE, Vieira LM, Hackbart KS, Bender RW, Dresch AR, Verstegen JP, Shaver RD, Wiltbank MC. 2014. Relationship between circulating anti-Müllerian hormone (AMH) and superovulatory response of high producing dairy cows. J Dairy Sci, 98:169-178.

Surjus RS, Prata AB, Borsato M, Mattos FC, Martins da Silveira MC, Mourão GB, Pires AV, Wiltbank MC, Sartori R. 2014. In vivo embryo production in cows superovulated 1 or 2 days after ovum pick-up. Reprod Fertil Dev, 26:527-532.

Viana J. 2018. 2017 Statistics of embryo production and transfer in domestic farm animals. Embryo Technology Newsletter, 36:8-25.

Vieira LM, Rodrigues CA, Castro Netto A, Guerreiro BM, Silveira CRA, Moreira RJC, Sá Filho MA, Bó GA, Mapletoft RJ, Baruselli PS. 2014. Superstimulation prior to the ovum pick-up to improve 
in vitro embryo production in lactating and nonlactating Holstein cows. Theriogenology, 82:318-324.

Vieira LM, Rodrigues CA, Castro Netto A, Guerreiro BM, Silveira CRA, Freitas BG, Bragança LGM, Marques KNG, Sá Filho MF, Bó GA, Mapletoft RJ, Baruselli PS. 2015. Efficacy of a single intramuscular injection of porcine FSH in hyaluronan prior to ovum pick-up in Holstein cattle. Theriogenology, 84:1-10.

Stewart BM, Block J, Morelli P, Navarette AE, Amstalden M, Bonilla L, Hansen PJ, Bilby TR. 2011. Efficacy of embryo transfer in lactating dairy cows during summer using fresh or vitrified embryos produced in vitro with sex-sorted semen. J Dairy Sci, 94:3437-3445.

Watanabe $\mathbf{Y}$, Souza $\mathrm{H}$, Mingoti RD, Ferreira R, Batista EOS, Dayan A, Watanabe O, Meirelles FV, Nogueira MFG, Ferraz JBS, Baruselli PS. 2017. Number of oocytes retrieved per donor during OPU and its relationship with in vitro embryo production and field fertility following embryo transfer. Anim Reprod, 14(3):635-644.

Wheeler MB, Rutledge JJ, Fischer-Brown A, VanEtten T, Malusky S, Beebe DJ. 2006. Application of sexed semen technology to in vitro embryo production in cattle. Theriogenology, 65:219-227. 